\title{
Value of A103 (melan-A) immunostaining in the differential diagnosis of ovarian sex cord stromal tumours
}

\author{
C J R Stewart, C L Nandini, J A Richmond
}

\begin{abstract}
Aims-To assess A103 (melan-A) immunoreactivity in a range of ovarian sex cord stromal tumours and to evaluate it for the differential diagnosis of other neoplasms. Methods-Paraffin embedded tissue sections from 45 sex cord stromal tumours and 44 potential histological mimics were examined immunohistochemically using the antibody A103. The sex cord stromal group included 21 adult granulosa cell tumours (AGCT), two juvenile granulosa cell tumours (JGCT), eight tumours showing Sertoli cell or Sertoli-Leydig cell differentiation, two unclassified tumours, two gonadoblastomas, one sex cord tumour with annular tubules, two steroid cell tumours, five thecomas/fibrothecomas, and two sclerosing stromal tumours. The histological mimics include 14 primary ovarian carcinomas, 13 metastatic carcinomas, four carcinoid tumours, four lymphomas, three endometrioid stromal sarcomas, two ovarian tumours of probable Wolffian origin, and one case each of small cell carcinoma, desmoplastic small round cell tumour, melanoma, and primitive neuroectodermal tumour.
\end{abstract}

Results-A103 immunoreactivity was identified in 25 sex cord stromal tumours including 10 AGCT, two JGCT, six Sertoli/ Sertoli-Leydig cell tumours, two steroid cell tumours, three thecomas/fibrothecomas, and two sclerosing stromal tumours. Of the potential histological mimics, staining was present only in the two ovarian tumours of probable Wolffian origin and the melanoma. Immunoreactive stromal cells were noted in a minority of cases. Normal hilus cells and rete ovarii epithelium also expressed A103.

Conclusions-A103 is a moderately sensitive and specific marker of sex cord stromal differentiation within the range of tumours examined in this study and as such is a valuable adjunct to other immunocytochemical markers in the assessment of diagnostically problematic ovarian tumours. The staining of normal and neoplastic Wolffian elements merits further investigation. (f Clin Pathol 2000;53:206-211)

Keywords: ovarian tumours; A103; immunohistochemistry
Sex cord or gonadal stromal tumours account for approximately $4 \%$ of benign ovarian neoplasms and $7 \%$ of primary ovarian malignancies. ${ }^{1}$ The sex cord element of these tumours may show granulosa or Sertoli cell differentiation, or may appear indeterminate, while the stromal cell component may consist of theca cells, Leydig cells, or non-specific gonadal stromal cells. ${ }^{2}$ As these cell types can occur as a pure population or in varying proportion, sex cord stromal tumours present a very wide range of histological appearances and may therefore mimic many other benign and malignant ovarian lesions. ${ }^{23}$ Conversely, unusual variants of relatively common ovarian neoplasms such as endometrioid carcinoma may closely resemble Sertoli-Leydig cell tumour (SLCT) or adult granulosa cell tumour (AGCT), while in younger patients the differential diagnosis can also include small cell carcinoma of hypercalcaemic type, desmoplastic small round cell tumour, and some germ cell neoplasms..$^{3-6}$ Thus sex cord stromal tumours create disproportionate diagnostic difficulty to histopathologists.

Immunohistochemistry has been used as an adjunct in the assessment of sex cord stromal tumours, particularly AGCT. While some antisera, such as those to intermediate filaments, are of value in specific diagnostic dilemmas, until recently there were no specific markers of sex cord stromal differentiation. However, in the past few years antibodies to the hormone inhibin ${ }^{7-13}$ and to the Ewing's sarcoma associated antigen CD $99^{14-16}$ have been shown to label the great majority of these neoplasms. As most potential histological mimics of sex cord stromal tumours are not immunoreactive with these markers they have proved extremely useful tools in problematic diagnostic cases. Nevertheless, a minority of sex cord stromal tumours are not labelled with these antisera and, in some series, a small proportion of other tumour types has been reactive. For example, Pelkey et al reported inhibin immunoreactivity in $6 \%$ of non-ovarian neoplasms and in four of 84 ovarian tumours of non-sex-cord stromal type. ${ }^{11}$ Equally, CD 99 expression is seen in many neoplasms, some of which may enter the differential diagnosis of sex cord stromal tumour. ${ }^{14}$ Thus a panel of antisera should be used in conjunction with morphological assessment in the diagnosis of problematic ovarian tumours.

Recent studies have suggested that the antibody A103, which is widely used in the diagnosis of melanocytic lesions, could prove a
Accepted for publication 13 September 1999 
useful additional marker of sex cord stromal differentiation. ${ }^{17} 18$ The antibody recognises an antigen, melan-A, which appears to play an important role in the immune response to malignant melanoma. ${ }^{19}$ Melan-A can be demonstrated using immunohistochemical techniques in almost all benign melanocytes and in up to $80 \%$ of melanomas. ${ }^{20-22}$ Although the tissue distribution of melan-A appears restricted, Jungbluth and colleagues ${ }^{17}$ noted that steroid hormone producing cells in the normal adrenal cortex and gonads were A103 immunoreactive, and they suggested that this reaction could prove of value in the diagnosis of adrenal and gonadal neoplasms. These investigators subsequently reported A103 expression in four testicular Leydig cell tumours, three of four ovarian SLCT, and a series of adrenocortical adenomas and carcinomas. ${ }^{18}$ To further assess the potential diagnostic value of this antibody in ovarian neoplasia we have examined A103 immunoreactivity in a wide range of ovarian sex cord stromal tumours and in tumours with which they might be confused histologically.

\section{Methods}

TISSUE SAMPLES

Paraffin embedded blocks of ovarian tumours were obtained from the files of Glasgow Royal Infirmary, from cases referred to the ovarian tumour panel between 1971 and 1980, and from tumours provided by colleagues in other pathology departments in Scotland. Two main groups of tumour were examined as summarised in table 1 .

Sex cord stromal tumours $(n=45)$

The AGCT showed a variable histological appearance but the predominant patterns in the blocks examined were diffuse $(n=8)$, trabecular (6) microfollicular (5), and macrofollicular (2). Of the seven SLCT, two were well differentiated, three of intermediate differentiation, and two poorly differentiated. Of the unclassified sex cord stromal tumours, one showed a primitive spindle cell pattern while the other mainly comprised indeterminate sex cord elements with occasional Sertoli cell, granulosa cell, and SCTAT-like (sex cord tumour with annular tubules) foci. These cor-

Table 1 A103 immunoreactivity of sex cord stromal tumours and potential histological mimics

\begin{tabular}{|c|c|c|c|}
\hline Sex cord stromal tumours & $\begin{array}{l}\text { Number stained/ } \\
\text { number tested }\end{array}$ & Histological mimics & $\begin{array}{l}\text { Number stained } \\
\text { number tested }\end{array}$ \\
\hline Primary AGCT & $8 / 18$ & $\begin{array}{l}\text { Primary carcinoma: } \\
\text {-Endometrioid }\end{array}$ & $0 / 8^{\star}$ \\
\hline Metastatic AGCT & $2 / 3$ & -Undifferentiated & $0 / 6^{\star}$ \\
\hline JGCT & $2 / 2$ & Metastatic carcinoma & $0 / 13$ \\
\hline Sertoli cell tumour & $1 / 1$ & Carcinoid tumour & $0 / 4^{\star}$ \\
\hline SLCT & $5 / 7$ & Malignant lymphoma & $0 / 4$ \\
\hline $\begin{array}{l}\text { Unclassified sex cord } \\
\text { stromal tumour }\end{array}$ & $0 / 2$ & $\begin{array}{l}\text { Endometrioid stromal } \\
\text { sarcoma }\end{array}$ & $0 / 3$ \\
\hline Gonadoblastoma & $0 / 2$ & $\begin{array}{l}\text { Ovarian tumour of } \\
\text { probable Wolffian origin }\end{array}$ & $2 / 2$ \\
\hline SCTAT & $0 / 1$ & Small cell carcinoma & $0 / 1$ \\
\hline Steroid cell tumour & $2 / 2$ & $\begin{array}{l}\text { Desmoplastic small cell } \\
\text { tumour }\end{array}$ & $0 / 1$ \\
\hline Thecoma/fibrothecoma & $3 / 5$ & Melanoma & $1 / 1$ \\
\hline Sclerosing stromal tumour & $2 / 2$ & $\begin{array}{l}\text { Primitive neuroectodermal } \\
\text { tumour }\end{array}$ & $0 / 1$ \\
\hline
\end{tabular}

${ }^{\star}$ Occasional immunoreactive stromal cells present in two endometrioid carcinomas, one undifferentiated carcinoma, and one metastatic carcinoid tumour. responded, respectively, to the types 1 and 2 unclassified gonadal stromal tumour, using the criteria of Seidman. ${ }^{23}$ The case of SCTAT was of sporadic type. The steroid cell tumours showed no specific differentiation (steroid cell tumour, not otherwise specified).

Problematic ovarian tumours $(n=44)$

Whenever possible the tumours selected had caused difficulty at the time of initial assessment and in many cases the differential diagnosis had included tumours of sex cord stromal type.

The primary carcinomas included six undifferentiated tumours and eight endometrioid carcinomas. Two of the latter showed a sertoliform pattern ${ }^{5}$ and two were of spindle cell type. ${ }^{6}$ The metastatic carcinomas were derived from primary tumours in the gastrointestinal tract $(n=4)$, breast (3), lung (1), or were of unknown origin (5). The carcinoid tumours comprised two metastases of intestinal tract origin and two primary tumours. The lymphomas included one Burkitt's lymphoma and three diffuse large B cell lymphomas. Two of the endometrioid stromal sarcomas were primary ovarian neoplasms while the third was a metastasis from a uterine primary; the latter showed a focal sex cord like pattern. The malignant melanoma was primary in the ovary arising within a mature cystic teratoma.

\section{IMMUNOHISTOCHEMISTRY}

Four micron sections were rehydrated and endogenous peroxidase blocked using 3\% hydrogen peroxide. Antigen retrieval was performed using a microwave heated plastic pressure cooker which was filled with 1 litre of EDTA at pH 8. Slides were placed in solution for five minutes at full pressure and then allowed to cool for a further 20 minutes. Endogenous biotin activity was blocked using a commercially available avidin/biotin blocking kit (Vector SP-2001) according to the manufacturer's instructions.

The primary antibody was the mouse monoclonal antibody A103 (Novo Castra), which was diluted $1 / 20$ in diluent solution (Dako $S$ 0809) and incubated at room temperature for one hour. The secondary antibody was a biotin labelled combined antimouse and antirabbit kit, followed by a streptavidin peroxidase conjugate (Dako LSAB 2) which was used according to the manufacturer's instructions. The chromogen was diaminobenzidene and, following development, slides were placed in $0.5 \%$ copper sulphate in normal saline to intensify staining.

Sections of a malignant melanoma were used as a positive control. The primary antiserum was omitted in negative controls.

\section{Results}

The results of A103 immunostaining are summarised in table 1 . In all cases the staining was confined to the cytoplasm, typically with a granular distribution although occasional focal perinuclear (punctate) staining was seen, particularly in AGCT. 


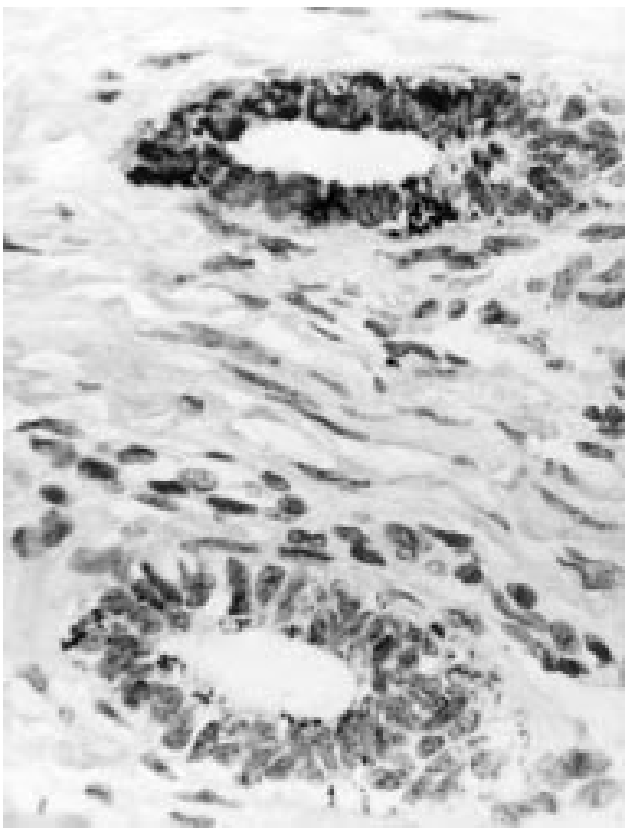

Figure 1 A103 immunoreactivity is focally present in tubules of the normal rete ovarii.

Although non-neoplastic ovary was not formally examined in this study it was noted that normal hilus cells were strongly immunoreactive with the A103 antibody. More focal staining was observed in tubular cells of the rete ovarii in two cases (fig 1) and very occasional normal and hyperplastic cortical stromal cells were also reactive.

Ten of the 21 AGCT (eight of 18 primary tumours and two of three metastases) showed cytoplasmic A103 immunoreactivity, this being of weak to moderate intensity in four tumours and of moderate to strong intensity in six. Staining was typically focal, being observed in less than $50 \%$ of cells in most tumours (fig 2 ). In only three AGCT were more than $75 \%$ of

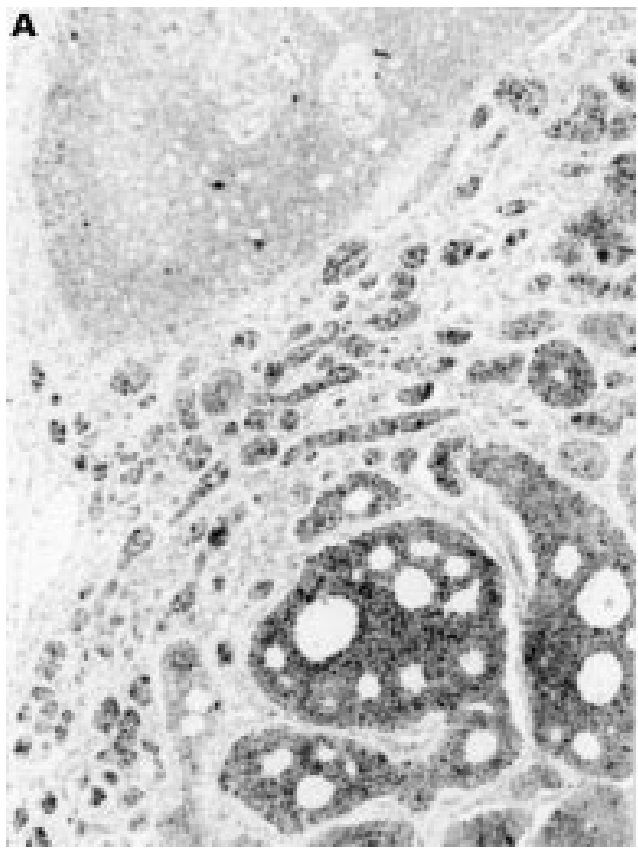

Figure 2 Adult granulo (B) trabecular areas. cells estimated to show A103 immunoreactivity. There was no obvious correlation between the intensity or distribution of staining and the histological subtype of the AGCT other than relatively strong reactivity within most areas showing a trabecular pattern. Both juvenile granulosa cell tumours (JGCT) showed weak immunoreactivity in a minority of cells.

Five of seven SLCT and the single pure Sertoli cell tumour were A103 immunoreactive. Strong extensive Sertoli cell staining was present in both well differentiated SLCT and also in the Sertoli cell tumour. However, less than $10 \%$ of Sertoli cells were labelled in three SLCT of intermediate or poor differentiation and two cases were unstained. In contrast, peripherally distributed Leydig cell clusters were strongly stained in all five reactive tumours (fig 3).

The two steroid cell tumours showed strong diffuse staining (fig 4). Three of five fibrothecomas and both sclerosing stromal tumours showed focal staining. In the latter cases the labelled cells were typically identified within the cellular perivascular foci. In fibrothecomas the reactive cells were rare and appeared randomly distributed in two tumours, but strong staining of more than $50 \%$ cells was observed in the remaining case. No staining was observed in the gonadoblastomas, the unclassified sex cord stromal tumours, or the SCTAT.

The two ovarian tumours of probable Wolffian origin showed finely granular A103 immunoreactivity in approximately one third of neoplastic cells (fig 5). Strong diffuse staining was also observed in the case of primary ovarian melanoma. Otherwise none of the neoplastic cells in tumours potentially mimicking sex cord stromal tumour were stained, although occasional reactive stromal cells were observed in two endometrioid carcinomas, one metastatic

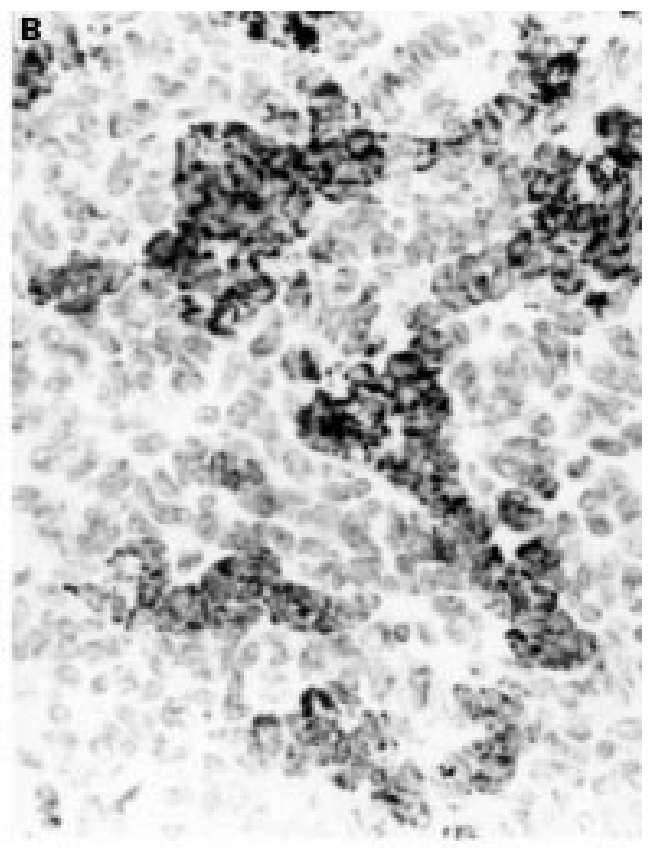




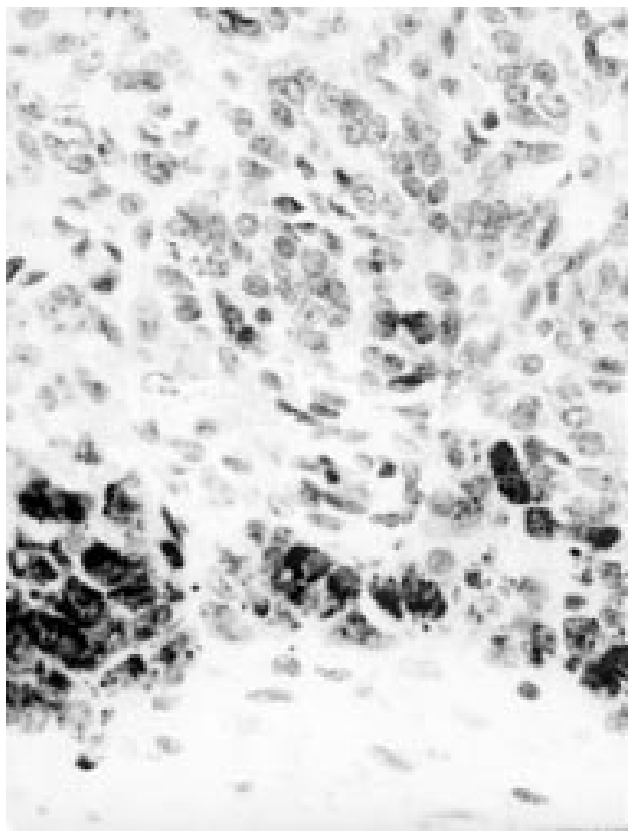

Figure 3 Peripheral Leydig cell clusters (below) are strongly A103 immunoreactive in a poorly differentiated Sertoli-Leydig cell tumour. Sertoli cell elements (above) are mainly unstained.

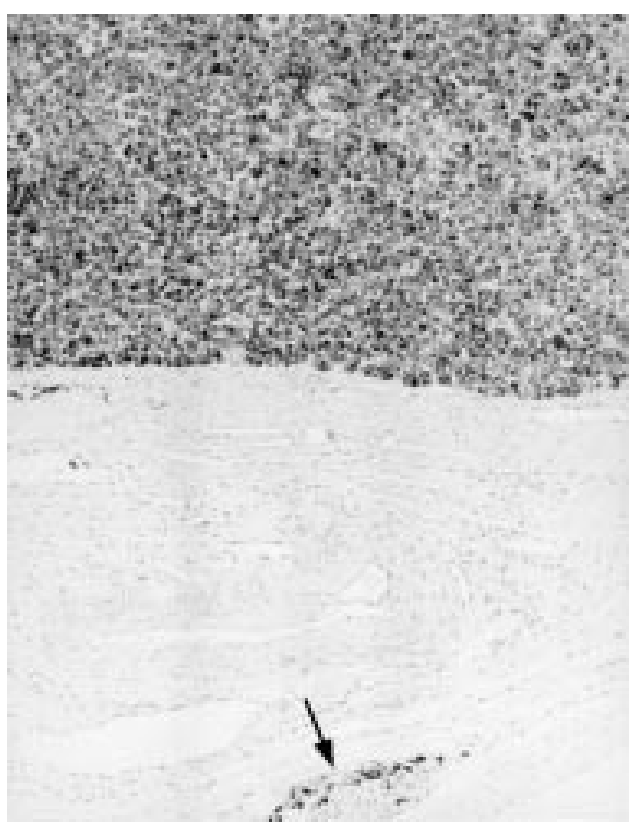

Figure 4 Steroid cell tumour (above) shows diffuse, strong A103 expression. Immunoreactive hilus cells are also present adjacent to medullary nerves (arrow).

carcinoid tumour, and one undifferentiated carcinoma (fig 6).

\section{Discussion}

The antibody A103 has been most widely used in the assessment of melanocytic lesions. It recognises an antigen, designated melan-A or MART-1, which is expressed by normal melanocytes and by most benign and malignant melanocytic proliferations. ${ }^{19-22}$ More recently it has been shown that A103 labels normal steroid hormone producing cells, including adrenocortical cells and gonadal sex cord and stromal cells. ${ }^{17}$ A103 expression has also been

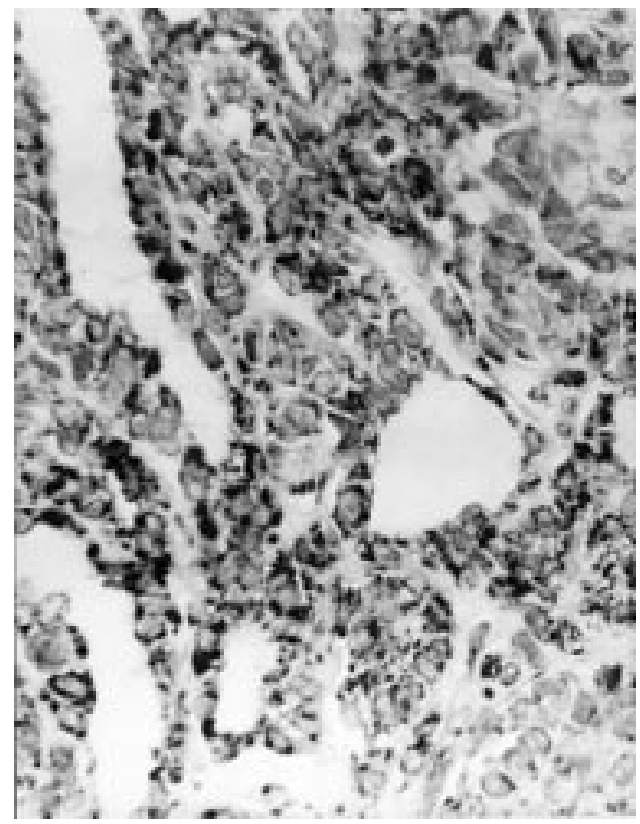

Figure 5 Ovarian tumour of probable Wolffian origin shows strong A103 immunoreactivity. Other areas of tumour were only focally stained.

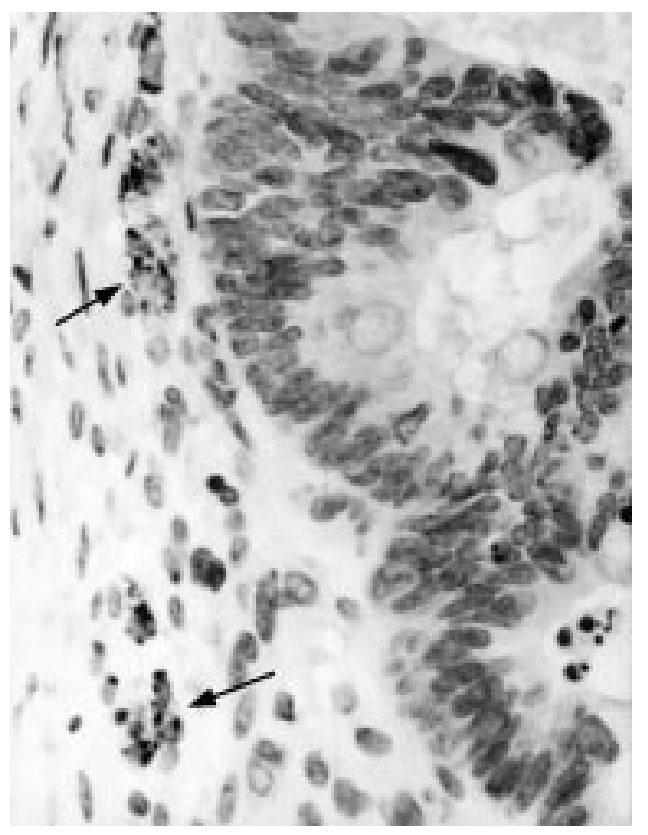

Figure 6 Focal A103 expression is seen in reactive stromal cells (arrows) but endometrioid carcinoma (right) is not stained.

described in adrenocortical neoplasms and testicular Leydig cell tumours, ${ }^{18-22}$ and Busam et al recorded staining in three of four ovarian SLCT.$^{18}$ Interestingly it appears that staining of these steroidogenic cells may represent an immunological cross reaction as m-RNA for melan-A/MART-1 has not been detected in non-melanocytic sites including the testis and the adrenal gland. ${ }^{24}{ }^{25}$ Nevertheless, as noted by Jungbluth et al, ${ }^{17}$ A103 immunoreactivity could prove of value in the differential diagnosis of steroid hormone producing tumours. This possibility led us to examine a series of ovarian sex cord stromal tumours and morphologically related ovarian neoplasms. 
A103 stained approximately $50 \%$ of ovarian sex cord stromal tumours examined in this study, including adult and juvenile granulosa cell tumours and tumours showing Sertoli cell differentiation. In contrast, and with the exception of a primary ovarian malignant melanoma and two ovarian tumours of probable Wolffian origin, none of the potential mimics of these neoplasms was immunoreactive. Thus A103 appears a moderately sensitive and specific marker of sex cord stromal differentiation within the range of tumours examined in this study. A positive staining reaction therefore supports a diagnosis of sex cord stromal tumour, but the absence of reactivity is of little diagnostic value. A surprising finding was the variation in A103 expression between morphologically similar tumours, and it was noteworthy that many of the unstained sex cord stromal tumours were accessed early in the series, mainly from blocks submitted to the ovarian tumour panel. It is possible that the staining reaction with A103 was affected by storage or by differences in fixation and processing in the older archival material. There was no clear association between immunoreactivity and histological subtype of AGCT, and staining was focal in most cases. In contrast A103 expression appeared to correlate with differentiation in SLCT, although the number of cases studied was small. Interestingly, only one of the four previously examined SLCT was non-reactive with A103, and this was a poorly differentiated tumour. ${ }^{18}$ Staining in SLCT was more uniform and intense in Leydig cells than in Sertoli cell elements, a similar pattern to that noted by Busam and colleagues. ${ }^{18}$

The gonadoblastomas and single SCTAT examined in this series were unstained by A103. As immunoreactivity may be associated with steroid hormone production this finding may reflect the relative immaturity of the sex cord elements in these tumours. Nevertheless some cases of SCTAT and gonadoblastoma are associated with clinical evidence of steroid hormone effect. $^{26} 27$ There was strong diffuse staining of both steroid cell tumours and more focal reactivity in a minority of fibromas and thecomas with A103. Very occasional cells were also stained in normal and hyperplastic ovarian stroma and within reactive stromal cells in a minority of primary and metastatic ovarian carcinomas. Occasional cells in sclerosing stromal tumour were also labelled, particularly in a perivascular distribution, a similar pattern to that of $\alpha$ inhibin immunoreactivity. ${ }^{9}$ However, these tumours are rarely associated with clinically evident endocrine effects.

The presence of A103 immunoreactivity in normal hilus cells was not surprising and was consistent with the observations of Jungbluth et $a l .{ }^{17}$ Less expected was the staining of mesonephric remnants (rete ovarii) and of two ovarian tumours of probable Wolffian (mesonephric) origin. While larger studies are required, our limited data suggest that A103 might prove useful in the assessment of mesonephric lesions, at least in the ovary. However, as inhibin immunoreactivity was reported in nine of 10 ovarian or paraovarian tumours of prob- able Wolffian origin by Kommoss et al, ${ }^{13}$ it would appear that neither A103 nor inhibin is of value in distinguishing neoplasms of putative mesonephric type from those of sex cord stromal origin.

The single case of malignant melanoma examined in this series was A103 immunoreactive as expected from previous studies of melanoma at other sites. Staining would also be expected in the majority of melanomas metastatic to the ovary, although to our knowledge this has not yet been reported. Although melanoma may be confused with ovarian sex cord stromal tumours, particularly JGCT, the clinical history and other morphological characteristics of melanoma make this differential diagnosis straightforward in most instances. ${ }^{28}$ The use of other immunohistochemical markers such as HMB 45 and tyrosinase for melanoma, and inhibin and CD 99 for sex cord stromal tumours, would also be of value in problematic cases. It is worth noting, however, that up to $50 \%$ of granulosa cell tumours may express S 100 protein, a commonly used marker of melanocytic neoplasms, ${ }^{29}$ and that tumours of probable Wolffian origin may also be S100 immunoreactive. ${ }^{30}$

Three endometrial stromal sarcomas were unstained with A103 in our study. These included two primary ovarian neoplasms and one uterine tumour metastatic to the ovary, the latter showing a focal sex cord like pattern. Krishnamurthy and colleagues ${ }^{31}$ recently reported focal A103 immunoreactivity in four of seven primary uterine tumours resembling ovarian sex cord tumours. Some cases were also stained by antisera to inhibin and CD99, and on this basis the authors suggested that these tumours might be of true sex cord derivation. The cases examined by Krishnamurthy et al all had a predominant or exclusive pattern of sex-cord-like differentiation, in contrast to the single case in our series in which this was a focal feature. The authors also noted an apparent inverse correlation between the expression of inhibin and that of A103 in their cases. However, all three tumours in our series were previously noted to be unstained with inhibin antisera. ${ }^{9}$

In summary, A103 immunoreactivity appears a moderately sensitive and specific marker of sex cord stromal differentiation in ovarian neoplasia, and is therefore of value in the assessment of ovarian tumours. However, the antibody should be used as part of a panel in problematic diagnostic cases. The finding that A103 also labels mesonephric remnants and tumours of proposed mesonephric origin within the ovary requires further study.

We are grateful to the late Dr A T Govan for providing material from cases referred to the ovarian tumour panel, and to the following colleagues who kindly provided tissue blocks of additional cases included in the study: S Dahill, $\mathrm{R}$ Jackson, $M$ Jeffers, H Kamel, S Lang, J McCullough, D McLellan, B Michie, R Morton, A Mowat, R Reid, M Seywright, W Spilg, and $\mathrm{C}$ Sutherland.

1 Koonings PP, Campbell K, Mishell DR, et al. Relative frequency of primary ovarian neoplasms: a 10 year review. Obstet Gynecol 1989;74:921-6.

2 Fox H. Sex cord-stromal tumours of the ovary. $f$ Pathol 1985;145:127-48. 
3 Young RH, Scully RE. Ovarian sex cord-stromal tumors. Problems in differential diagnosis. Pathol Annu 1988;23. Problem

4 Young RH. Ovarian tumors other than those of surface epithelial-stromal type. Hum Pathol 1991;22:763-75.

5 Roth LM, Liban E, Czernobilsky B. Ovarian endometriod tumors mimicking Sertoli and Sertoli-Leydig cell tumors. Sertoliform variant of endometriod carcinoma. Cancer 1982;50:1322-31

6 Tornos C, Silva EG, Ordonez NG, et al. Endometriod carcinoma of the ovary with a prominent spindle-cell component, a source of diagnostic confusion. A report of 14 cases. Am ₹ Surg Pathol 1995;19:1343-53.

7 Flemming P, Wellmann A, Maschek H, et al. Monoclonal antibodies against inhibin represent key markers of adult granulosa cell tumors of the ovary even in their metastases. Am ₹ Surg Pathol 1995;19:927-33.

8 McCluggage WG, Maxwell P, Sloan JM. Immunohistochemical staining of ovarian granulosa cell tumors with monoclonal antibody against inhibin. Hum Pathol 1997;28: monoclona $1034-8$.

9 Stewart CJR, Jeffers MD, Kennedy A. Diagnostic value of inhibin immunoreactivity in ovarian gonadal stromal tumours and their histological mimics. Histopathology 1997;31:67-74

10 Rishi M, Howard LN, Bratthauer GL, et al. Use of monoclonal antibody against human inhibin as a marker for sex cord-stromal tumors of the ovary. Am $\mathcal{F}$ Surg Pathol 1997;21:583-9.

11 Pelkey TJ, Frierson HF, Mills SE, et al. The diagnostic utility of inhibin staining in ovarian neoplasms. Int 7 Gynecol Pathol 1998;17:97-105.

12 Hildebrandt RH, Rouse RV, Longacre TA. Value of inhibin in the identification of granulosa cell tumors of the ovary. Hum Pathol 1997;28:1387-95.

13 Kommoss F, Oliva E, Bhan AK, et al. Inhibin expression in ovarian tumors and tumor-like lesions: an immunohistoovarian tumors and tumor-like lesions: an
chemical study. Mod Pathol 1998;11:656-64.

14 Stevenson AJ, Chatten J, Bertoni F, et al. CD99 (p30/32 MIC2) neuroectodermal/Ewing's sarcoma antigen as an immunohistochemical marker. Review of more than 600 immunohistochemical marker. Review of more than 600 tumors and the liter

15 Loo KT, Leung AKF, Chan JKC. Immunohistochemical staining of ovarian granulosa cell tumours with MIC2 antibody. Histopathology 1995;27:388-90.

16 Gordon MD, Corless C, Renshaw AA, et al. CD99, keratin and vimentin staining of sex cord-stromal tumors, normal ovary, and testis. Mod Pathol 1998;11:769-73.

17 Jungbluth AA, Busam KJ, Gerald WL, et al. A103: an antimelan A monoclonal antibody for the detection of malignant melanoma in paraffin-embedded tissues. Am $\mathcal{F}$ Surg Pathol 1998;22:595-602.
18 Busam KJ, Iversen K, Coplan KA, et al. Immunoreactivity for A103, an antibody to melan-A (Mart-1), in adrenocortical and other steroid tumors. Am f Surg Pathol

19 Chen Y-T, Stockert E, Jungbluth A, et al. Serological analysis of melan-A (MART-1), a melanocytic-specific protein homogeneously expressed in human melanomas. Proc Natl Acad Sci USA 1996;93:5915-19.

20 Busam KJ, Chen Y-T, Old LJ, et al. Expression of melan-A MART1) in benign melanocytic nevi and primary cutaneous malignant melanoma. Am f Surg Pathol 1998;22:97682.

21 Blessing K, Sanders DS, Grant JJ. Comparison of immunohistochemical staining of the novel antibody melan-A with S100 protein and HMB-45 in malignant melanoma and melanoma variants. Histopathology 1998:32:139-46.

22 Kaufmann O, Koch S, Burghardt J, et al. Tyrosinase, melan-A, and KBA62 as markers for the immunohistochemical identification of metastatic amelanotic melanomas on paraffin sections. Mod Pathol 1998;11:740-6.

23 Seidman JD. Unclassified ovarian gonadal stromal tumors. A clinicopathologic study of 32 cases. Am f Surg Pathol A clinicopathologic

24 Coulie PG, Brichard V, Van Pel A, et al. A new gene coding for a differentiation antigen recognised by autologous cytolytic T lymphocytes on HLA-A2 melanomas. F Exp Med 1994;180:35-42.

25 Kawakami Y, Eliyahu S, Delgado $\mathrm{CH}$, et al. Cloning of the gene for a shared human melanoma antigen recognised by autologous T cells infiltrating into tumor. Proc Natl Acad Sci USA 1994;91:3515-19.

26 Young RH, Welch WR, Dickensin GR, et al. Ovarian sex cord tumor with annular tubules: review of 74 cases including 27 with Peutz-Jeghers syndrome and 4 with adenoma malignum of the cervix. Cancer 1982;50:1384402 .

27 Scully RE. Gonadoblastoma. A review of 74 cases. Cancer 1970;25:1340-56.

28 Young RH, Scully RE. Malignant melanoma metastatic to the ovary. A clinicopathologic analysis of 20 cases. Am 7 Surg Pathol 1991;15:849-60.

29 Costa MJ, DeRose PB, Roth LM, et al. Immunohistochemical phenotype of ovarian granulosa cell tumors: absence of epithelial membrane antigen has diagnostic value. Hum Pathol 1994;25:60-6.

30 Rahilly MA, Williams ARW, Krausz T, et al. Female adnexal tumor of probable Wolffian origin: a clinicopathological and immunohistochemical study of three cases. Histopathology 1995;26:69-74.

31 Krishnamurthy S, Jungbluth AA, Busam KJ, et al. Uterine tumors resembling ovarian sex-cord tumors have an immunophenotype consistent with true sex-cord differentiation. Am f Surg Pathol 1998;22:1078-82. 